\title{
Tectonomagnetic and VLF electromagnetic signals in Central Italy
}

\author{
Antonio Meloni $\left({ }^{1}\right)$, Domenico Di Mauro $\left({ }^{1}\right)$, Stefania Lepidi $\left({ }^{2}\right)$, \\ Giuliana Mele $\left({ }^{1}\right)$ and Paolo Palangio $\left({ }^{2}\right)$ \\ ${ }^{1}{ }^{1}$ Istituto Nazionale di Geofisica e Vulcanologia, Roma, Italy \\ () Osservatorio Geofisico di L'Aquila, Istituto Nazionale di Geofisica e Vulcanologia, L'Aquila, Italy
}

\begin{abstract}
Tectonomagnetic field observations from absolute magnetic field level measurements were undertaken in Central Italy in an area extending between latitude $41^{\circ} \mathrm{N}$ and $43^{\circ} \mathrm{N}$ and between longitude $13^{\circ} \mathrm{E}$ and $15^{\circ} \mathrm{E}$. Moreover, natural electromagnetic signals from a system of two VLF search coil wide-band antennas were collected at the geomagnetic observatory of L'Aquila $\left(42^{\circ} 23^{\prime} \mathrm{N}, 13^{\circ} 19^{\prime} \mathrm{E}\right)$. The analysis of these data allowed the investigation of the electromagnetic properties of the study area at different time and spatial lengthscales. Tectonomagnetic field observations were obtained comparing data simultaneously recorded at three magnetometer stations using L'Aquila Observatory as a reference for differentiation. We report on the time evolution of magnetic and electromagnetic indicators related to local and regional seismic activity.
\end{abstract}

Key words tectonomagnetism - seismomagnetic network - seismic activity - VLF - Central Italy

\section{Introduction}

Magnetic and electromagnetic field natural signals are monitored in seismogenic areas in the search for possible correlations with seismic activity. This field of investigation covers phenomena that vary on a very wide range of frequencies from DC to VHF. This paper reports the results of the analysis of data coming from two subsets of electromagnetic investigations, the so-called tectonomagnetic field observations and VLF natural electromagnetic field waves observation.

As concerns tectonomagnetic field observations, we refer to changes in the physical prop-

Mailing address: Dr. Antonio Meloni, Istituto Nazionale di Geofisica e Vulcanologia, Via di Vigna Murata 605 , 00143 Roma, Italy; e-mail: meloni@ingv.it erties of the crustal materials that could lead to local anomalous variations of the Earth's magnetic field. Magnetic changes due to stress field variations in the uppermost crustal layers have been predicted and observed historically and the term tectonomagnetism was introduced for this research field. Some indirect effects of the electrokinetic type caused by fluid flows have also been invoked as a possible cause for local magnetic anomalies. The term seismomagnetism is in particular referred to magnetic field changes associated with earthquake occurrence.

Following the report that tectonic events, like earthquakes and volcanic eruptions, can produce observable variations in the absolute value of the geomagnetic field intensity, many groups have started such investigations. In the case of tectonomagnetic and seismomagnetic effects the scientific literature has many examples. Parrot and Johnston (1993), Hayakawa and Fujinawa (1994), Gasparini et al. (1997), Johnston (1997), Johnston and Parrot (1997), Mueller and Johnston (1998), Meloni et al. (2001) are dedicated to such topics. Seismomagnetic effects are detected with sensitive magnetometric instrumen- 
tation in the near field of earthquakes only when magniude $M$ is greater than 6 with an amplitude of about $1 \mathrm{nT}$ or so (Johnston, 2002).

According to many investigations, electromagnetic phenomena in a wide range of frequencies ranging from ULF to VHF that take place in the atmosphere and ionosphere also show anomalous emissions in association with earthquakes. We will refer in this paper to measurements in the VLF band only. In this band transient signals and noise are generated by various natural and artificial phenomena of which radio atmospherics (or sferics for short and sometime statics) are one kind of typical impulsive electromagnetic signals that can propagate in the atmosphere for thousand kilometers. Generated by atmospheric lightning strokes, radio atmospherics travel in the Earthionosphere wave guide as a VLF wave with power concentrated mainly in the VLF range, from 0.1 to $10 \mathrm{kHz}$ (see for a recent review Barr et al., 2000). Gokhberg et al. (1989) were among the first to report perturbations on VLF waves amplitude in association with earthquakes. Other reports, by Hayakawa and Fujinawa (1994), Morgunov et al. (1994) and Parrot (1995), followed. Anomalous VLF signals were also detected in the case of the 1995 Kobe earthquake (see Nagao et al., 2002). Electromagnetic waves at ELF and VLF frequencies related to earthquakes were also detected from satellite instrumentation, see for example Molchanov et al. (1993) and Parrot (1994).

\section{Area of investigation and geodynamic framework}

The study area extends between latitudes $41^{\circ} \mathrm{N}$ and $43^{\circ} \mathrm{N}$ and longitudes $12^{\circ} \mathrm{E}$ and $16^{\circ} \mathrm{E}$ (fig. 1). This area has been investigated in the last twelve years starting in July 1989 with the

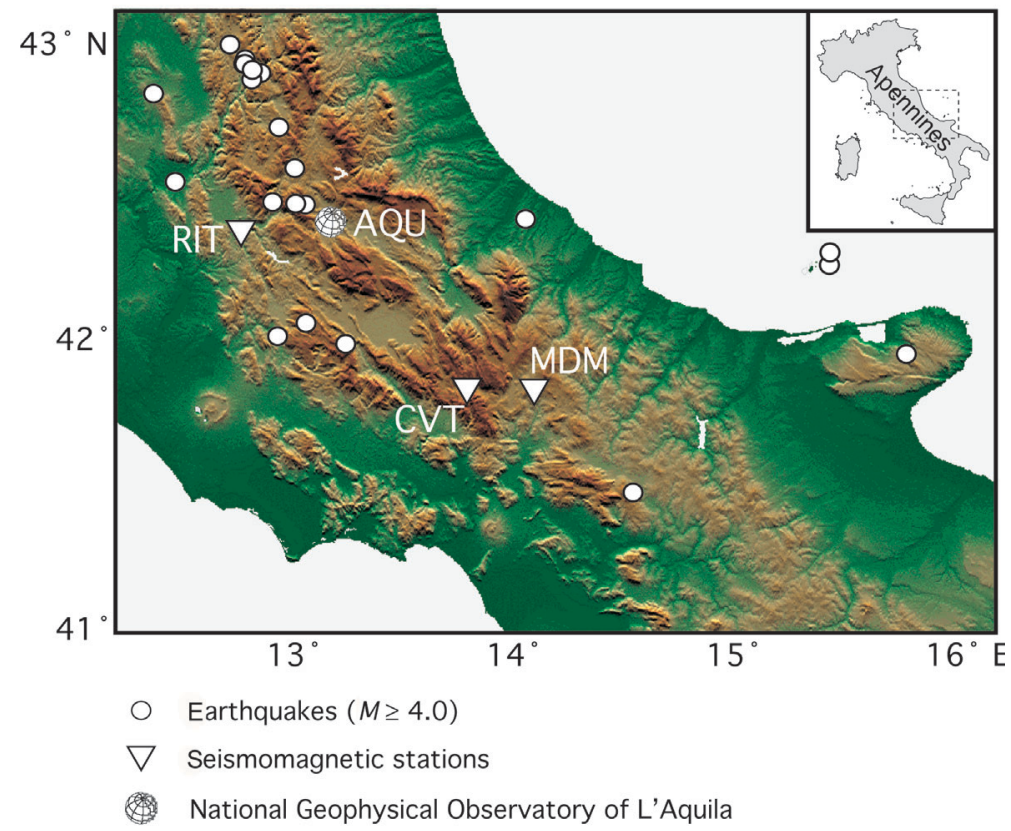

Fig. 1. Topography map of the study area showing L'Aquila Observatory and seismomagnetic stations used in this work; epicenters (white dots) of magnitude $M \geq 4.0$ earthquakes occurred from 1989 to 2001 are also reported (see list in table I). 
intent of detecting electromagnetic and magnetic natural signals related to local seismic activity. Such studies used magnetotelluric stations, magnetometer total field stations and VLF natural wave detection systems (Mele et al., 1994; Meloni et al., 1996, 2001; Ernst et al., 1997).
Central Italy has a long history of moderateto-intense seismicity (Boschi et al., 1997; IN$\mathrm{GV}, 2003$ ) that makes this area suitable for studies of possible relations between electromagnetic natural phenomena and seismic activity. Even though rock magnetization in the

Table I. Earthquakes with $M \geq 4.0$ occurring in Central Italy in the study period.

\begin{tabular}{|c|c|c|c|c|c|c|}
\hline$\#$ & $\begin{array}{l}\text { Date } \\
\text { d.m.y }\end{array}$ & $\begin{array}{c}\text { Origin Time } \\
\text { UT }\end{array}$ & Lat. $\mathrm{N}$ & Long. E & $\begin{array}{l}\text { Depth } \\
\text { km }\end{array}$ & $M$ \\
\hline 1 & 06.10 .1989 & $17: 38: 27$ & 42.17 & 15.59 & 5 & 4.1 \\
\hline 2 & 22.12 .1989 & $06: 48: 15$ & 43.02 & 12.77 & 5 & 4.0 \\
\hline 3 & 01.02 .1990 & $06: 24: 15$ & 42.13 & 15.58 & 5 & 4.1 \\
\hline 4 & 16.07.1992 & 05:38:55 & 42.34 & 14.21 & 5 & 4.0 \\
\hline 5 & 05.06.1993 & 19:16:18 & 43.13 & 12.67 & 5 & 4.3 \\
\hline 6 & 02.06.1994 & $17: 38: 15$ & 42.44 & 13.21 & 5 & 4.0 \\
\hline 7 & 07.08.1994 & $06: 31: 12$ & 41.95 & 13.37 & 5 & 4.0 \\
\hline 8 & 30.09 .1995 & $10: 14: 34$ & 41.80 & 15.90 & 22 & 4.4 \\
\hline 9 & 20.10 .1996 & 19:06:56 & 42.56 & 13.16 & 5 & 4.0 \\
\hline 10 & 19.03.1997 & $23: 10: 49$ & 41.38 & 14.63 & 9 & 4.1 \\
\hline 11 & 12.05 .1997 & 13:50:16 & 42.83 & 12.54 & 5 & 4.6 \\
\hline 12 & 26.09.1997 & $00: 33: 11$ & 43.02 & 12.91 & 8 & 5.6 \\
\hline 13 & 26.09.1997 & 09:40:24 & 43.02 & 12.93 & 5 & 5.8 \\
\hline 14 & 03.10 .1997 & 08:55:20 & 43.02 & 12.90 & 5 & 5.0 \\
\hline 15 & 04.10 .1997 & 15:07:19 & 42.92 & 12.98 & 4 & 4.1 \\
\hline 16 & 04.10 .1997 & $16: 13: 31$ & 42.92 & 12.98 & 4 & 4.3 \\
\hline 17 & 04.10 .1997 & $18: 47: 46$ & 42.92 & 12.97 & 5 & 4.3 \\
\hline 18 & 12.10 .1997 & 11:08:35 & 42.90 & 13.01 & 5 & 4.7 \\
\hline 19 & 13.10 .1997 & 11:01:44 & 42.88 & 13.05 & 3 & 4.0 \\
\hline 20 & 13.10 .1997 & 13:09:19 & 42.86 & 13.00 & 4 & 4.0 \\
\hline 21 & 14.10 .1997 & $15: 23: 09$ & 42.91 & 12.97 & 5 & 5.5 \\
\hline 22 & 15.10 .1997 & 22:53:09 & 42.92 & 12.00 & 6 & 4.1 \\
\hline 23 & 21.03 .1998 & $16: 45: 09$ & 42.98 & 12.90 & 5 & 4.1 \\
\hline 24 & 15.08 .1998 & $05: 18: 10$ & 42.44 & 13.04 & 5 & 4.5 \\
\hline 25 & 10.10 .1999 & $15: 35: 52$ & 42.69 & 13.13 & 5 & 4.0 \\
\hline 26 & 11.03 .2000 & $10: 35: 28$ & 42.03 & 13.17 & 5 & 4.3 \\
\hline 27 & 27.06.2000 & $07: 32: 32$ & 41.00 & 13.04 & 5 & 4.0 \\
\hline 28 & 16.12 .2000 & 07:31:06 & 42.53 & 12.62 & 8 & 4.0 \\
\hline
\end{tabular}


study area is moderate to low (Molina et al., 1994; Chiappini et al., 2000), due to the presence of carbonates and marls along with flysch deposits, the generally very low level of artificial electromagnetic noise, makes it suitable for natural magnetic and electromagnetic field investigations.

Earthquake distribution in peninsular Italy mainly follows the NW-SE axis of the Apennine mountain belt. Focal mechanisms indicate that this chain is currently dominated by extensional deformation (e.g., Anderson and Jackson, 1987; Amato et al., 1998) overimposed on older compressional features of Paleogene age. In the Central Apennines, where the study area is located, a $M=6.9$ earthquake occurred in 1915 (e.g., Ward and Valensise, 1989) causing more than 32000 fatalities (Boschi et al., 1997). Moderate-magnitude events also occurred in recent years: the $M=5.4$ Val Comino earthquake in 1984 (Console et al., 1989) and the 19971998 Umbria-Marche seismic sequence, with the six largest earthquakes of magnitude ranging between 5.0 and 6.0 (e.g., Amato et al., 1998). In table I all $M \geq 4.0$ earthquakes occurred from 1989 to 2001 are reported; epicenters are shown in fig. 1.

Many studies have shown that in the phases of preparation of a seismic event and also in case of coseismic observations, patterns of time variations of electromagnetic or magnetic parameters vary generally greatly in shape, time scales, phases and extent around the hypocentral area. Moreover, quantitatively defining an 'anomaly' is sometimes very difficult. For such reasons, besides the identification of magnetic and VLF wave signals and their relations to seismic activity, our investigation was also finalized to improve the knowledge of the natural background electromagnetic phenomena in this region.

\section{Data analysis}

\subsection{Observations by proton procession magnetometer network}

Proton Procession Magnetometers (PPMs) and optical pumping magnetometers are gen- erally used for reliable tectonomagnetic studies (Parsons and Wiatr, 1982; Mueller and Johnston, 1998). The installation of a seismomagnetic network in the area of study started in middle 1989. Data are gathered by means of PPMs installed in a network with station separation of a few tens of kilometers. Magnetometers simultaneously measure the total magnetic field intensity with a sampling rate that has been variable in the last ten years (4-10-15 min) and is now set to $15 \mathrm{~min}$. The present network consists of three stations shown in fig. 1 with their acronyms. Measured values are averaged and differentiated with respect to L'Aquila Geomagnetic Observatory to filter out the contributions from external sources and from regional inhomogeneities of the Earth's magnetic field. After processing, the total magnetic field data are plotted and searched for possible local field changes in order to relate them to earthquake occurences in a defined area around the instruments magnetic network.

\subsection{Observations by VLF antennas in L'Aquila}

Time variability of natural signals in VLF band is monitored in the L'Aquila Observatory by means of two search coil wide band antennas operating in the range $15-40 \mathrm{kHz}$. The system has 4 band pass filters centered at 15, 20, 30 and $40 \mathrm{kHz}$ respectively. Radiometer sensitivity is $200 \mathrm{fT}$ at $40 \mathrm{~Hz}$ and data are sampled at $1 \mathrm{~Hz}$ and stored with a 16 bit resolution, after averaging every $60 \mathrm{~s}$. The main purpose of this monitoring procedure is to investigate the time behaviour of recorded natural radio signals in the VLF band to study its time evolution and stability. The time plots, here produced only for 20 and $40 \mathrm{kHz}$, were also related to seismic activity as recorded in the defined area around L'Aquila Observatory. Some authors have pointed out that VLF waves monitoring could be more advantageous if an artificial source is used (see Molchanov and Hayakawa, 1998; Saraev et al., 1999). However in this area the overall low artificial electromagnetic noise in this band has facilitated the VLF natural waves data acquisition. 


\subsection{Results}

Figure 2 reports the daily mean values for the Earth's magnetic field intensity from AQU and the seismomagnetic stations in their time evolution. A steady increasing secular variation of about $25 \mathrm{nT} / \mathrm{yr}$ is observed at all stations; synchronous spikes are due to solar activity, some interruptions are caused at the seismomagnetic stations because of instrumental fail- ure (this figure is an update of Meloni et al., 2001). Figure 3 shows five-day means of simple differences for the total geomagnetic field between the AQU reference station and RIT, MDM, and CVT stations. Vertical lines in the plot indicate the occurrence of the most intense earthquakes $\left(M_{d} \geq 4.0\right)$; see also table I for the complete list. The sequence of September-October 1997, where 4 earthquakes with $M_{d} 5.0$ to 6.0 took place in the Umbria-Marche region, on
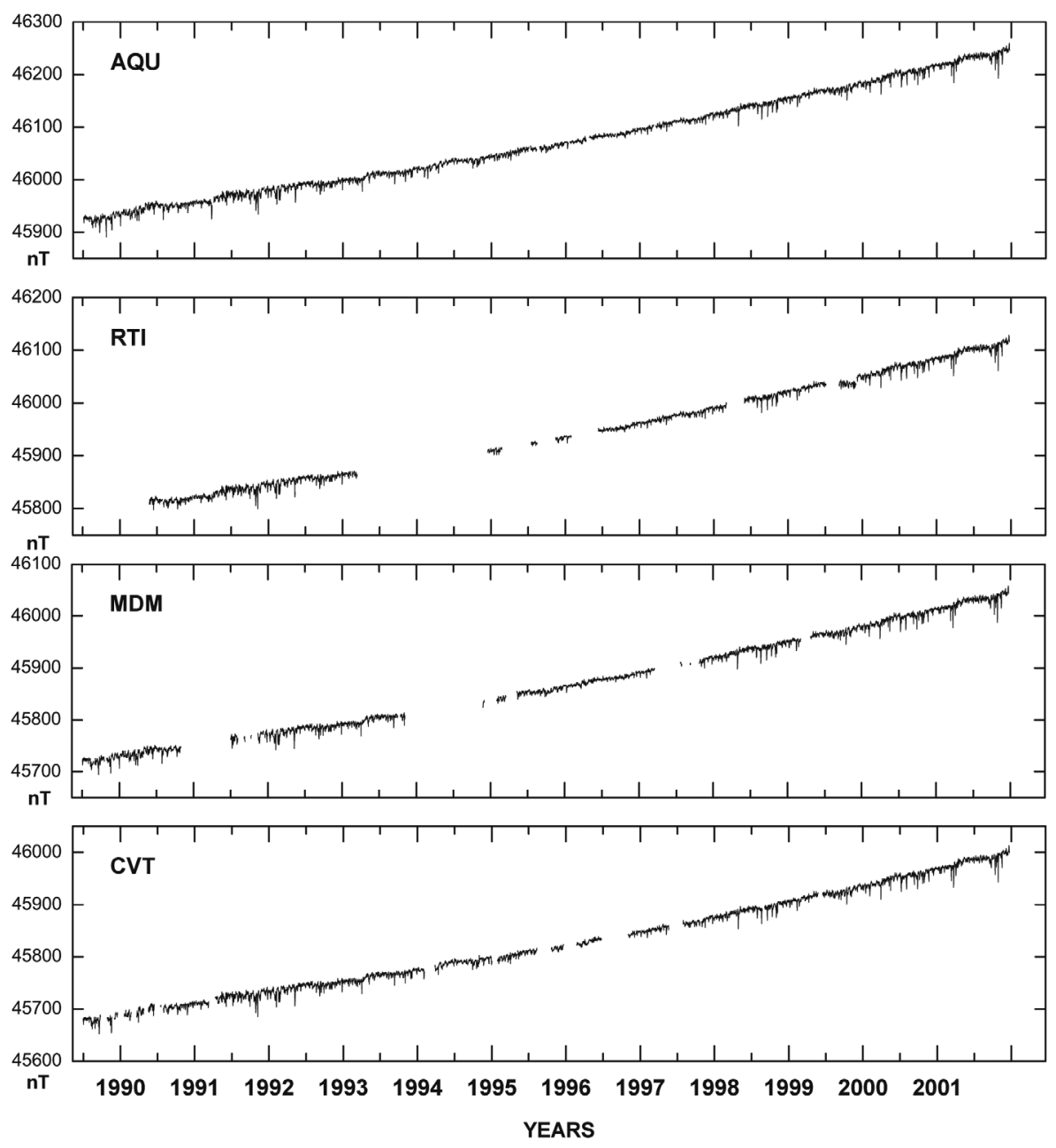

Fig. 2. Time variation of total magnetic field $F$ (daily means) at L'Aquila Observatory (AQU) and the seismomagnetic stations (RTI, MDM and CVT; see also fig. 1 for map location). 

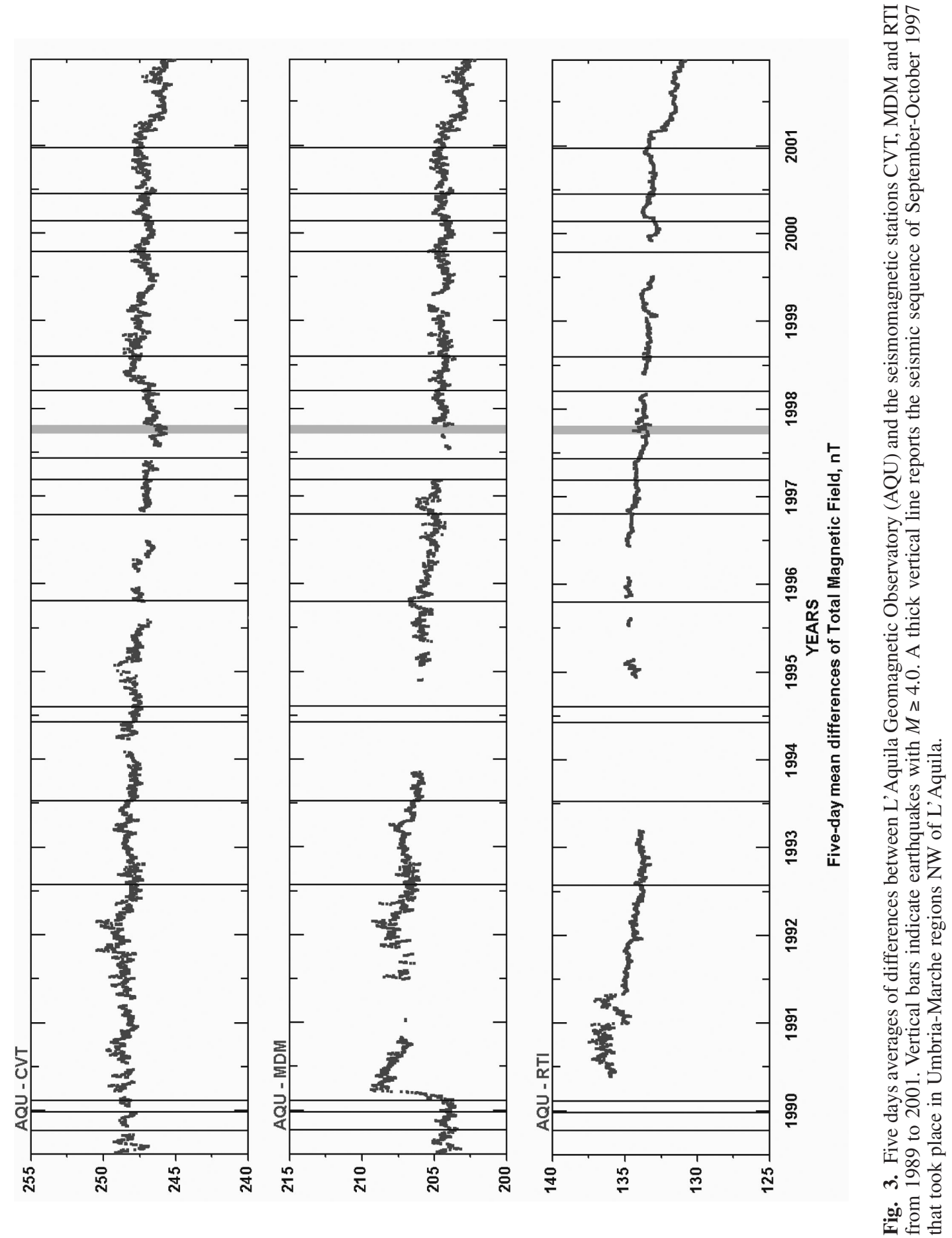

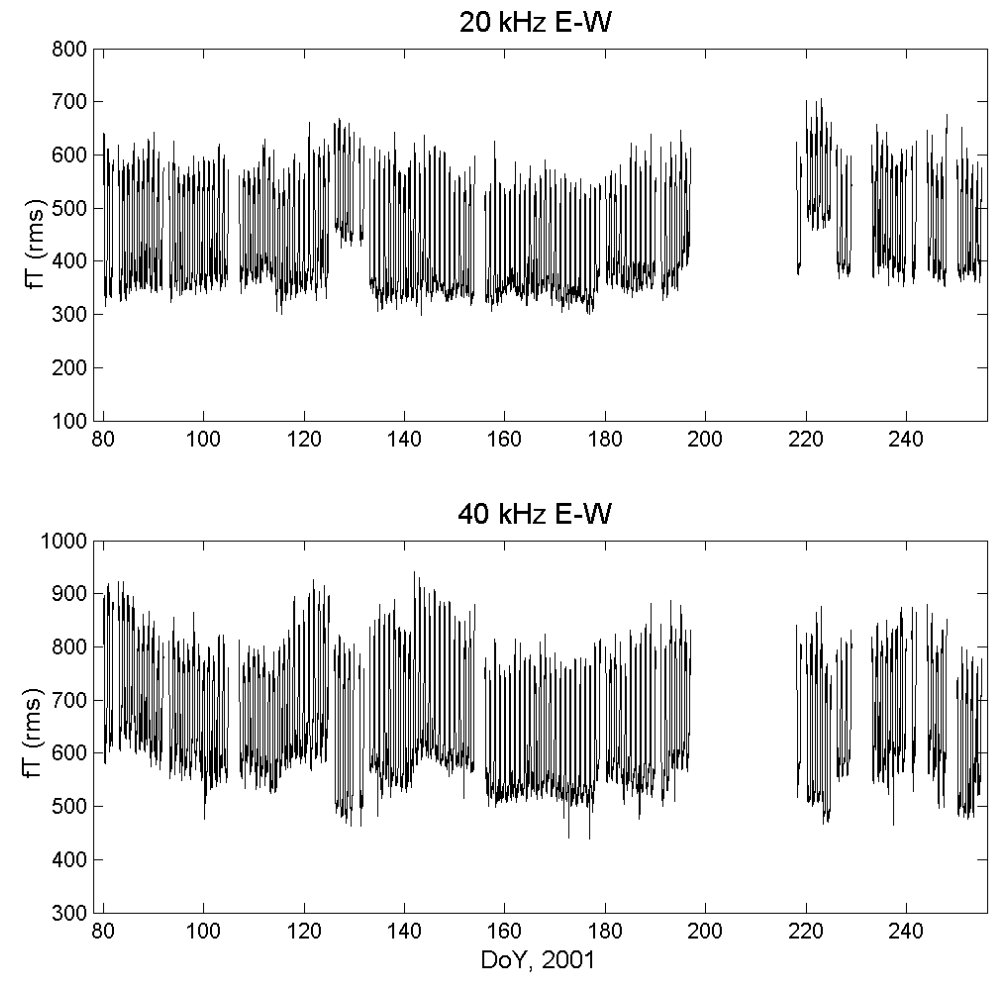

Fig. 4. VLF $20 \mathrm{kHz}$ and $40 \mathrm{kHz}$ one minute data for part of the year 2001 .

the NW sector of the monitored area, is reported as a gray band. In January-February 1990 and only at that time, an anomalous variation was clearly detected at MDM station.

Figure 4 reports the time variability of natural electromagnetic signals, measured at L'Aquila Observatory in the VLF band by means of two search coil wide band antennas, for 20 and 40 $\mathrm{kHz}$. This variability is shown for the year 2001 by means of 1 min data from March to September with an interruption caused by technical failure for twenty days in July and August.

\section{Discussion and conclusions}

The plots of magnetic field differences between seismomagnetic stations and L'Aquila Observatory show a scatter around the mean difference values; the scatter amplitude increases with the distance from L'Aquila Observatory showing the limits in the removal of external magnetic field variation gradients. Although a moderate seismicity occurred in the study period and sometimes anomalies have been detected from this network, there is no clear evidence of a one-to-one relation between magnetic anomalies and seismic events (see also Meloni et al., 1998). Some variations of moderate amplitude occur in correspondence with the UmbriaMarche in 1997 while no other significant effects appear in the following years here reported up to 2001. The weak evidence of magnetic field changes during the observational period indicates that magnetic long term crustal origin effects do not frequently occur in this area. Furthermore, the weak to moderate energy seismic activity that occurred in this observation period 
(1989-2001) is probably one of the causes that did not allow us to find an evident correlation between local magnetic field variations and earthquake occurrence.

VLF wave characteristics recorded at any station are mainly influenced by ionospheric parameters. Among these, the ionospheric height and consequently the profile of electron density in the lower $D$ layer are connected primarily to solar radiation. Of course many other possible external sources of ionization can also contribute (cosmic rays, whistler induced particle precipitation and other). An anomalous enhancement of VLF waves amplitude in L'Aquila was reported in Meloni et al. (2001) for September and October 1997. Since at that time no other ionospheric effects were detected at the ionospheric station of Rome (only about $100 \mathrm{~km}$ away) an external cause for the anomaly that should operate at a larger scale was reasonably excluded. The anomaly consisting in a significant increase in signal amplitude and daily range of the order of a factor three above the preceding quiet level, was instead observed in correspondence with the Umbria-Marche sequence $c a$. $75 \mathrm{~km}$ from the L'Aquila Observatory lasting for about two months. For this reason, Meloni et al. (2001) considered an influence from the Umbria-Marche earthquakes possible. A qualitative explanation of such effect may be related to rock creeping that takes place in the earthquake focal area and the intensive strain rate in the surrounding crust, that can give a mechanical background for the generation of electromagnetic anomalous fields. As concerns VLF signals, since more evidence is necessary before final conclusions can be reached, a continuous monitoring was set up to have a better assessment in case other possible earthquake electromagnetic related phenomena in this area were recorded. Figure 4 shows the time plots for 20 and $40 \mathrm{kHz}$ by their 1 min values, here shown only for part of 2001 as an example. No other sinificant variations comparable to those recorded in the 1997 events (see Meloni et al., 2001) were recorded and at the same time no other relevant earthquakes in the area were occurred.

In conclusion, seismomagnetic and VLF data gathered in recent years were used to obtain a better knowledge of the natural tectonomag- netic and electromagnetic phenomena observed in this region. Data were also analyzed to evaluate if results could be used to search for possible correlations to seismic activity. No evidence of time variations of crustal magnetic and earthquake occurrence was clearly found. Significant enhancements in correspondence to earthquakes occurrence were found for VLF waves in the case of the 1997 Umbria-Marche seismic sequence. Data for the subsequent years have not shown that those strong variations are frequently recorded at L'Aquila and at the same time no other significant earthquakes were recorded. More data are needed to reach convincing conclusions but continuous monitoring of VLF time variations will be continued for their promising role in the assessment of earthquake electromagnetic related phenomena in Central Italy.

\section{REFERENCES}

Amato, A., R. Azzara, C. Chiarabba, G.B. Cimini, C. Cocco, M. Di Bona, L. Margheriti, S. Mazza, F. Mele, G. Selvaggi, A. Basili, E. Boschi, F. Courboulex, A. Deschamps, S. Gaffet, G. Bittarelli, L. Chiaraluce, D. Piccinini and M. Ripepe (1998): The Colfiorito, Umbria-Marche earthquake sequence in Central Italy (September-November, 1997): a first look to mainshocks and aftershocks, Geophys. Res. Lett., 25 (15), 2861-2864.

ANDERSON, H. and J. JACKSON (1987): Active tectonics of the Adriatic region, Geophys. J. R. Astron. Soc., 91, 937-983,

Boschi, E., E. Guidoboni, G. Ferrari, G. Valensise and P. GASPERINI (1997): Catalogo dei Forti Terremoti in Italia dal 461 a.C. al 1990 (ING, Roma), pp. 644.

BARR, R., D. Llanwyn Jones and C.J. RodGer (2000): ELF and VLF radio waves, J. Atmos. Solar Terr. Phys., 62, 1689-1718.

Chiappini, M., A. Meloni, E. Boschi, O. Faggioni, N. BeVERINI, C. CARMISCIANO and I. MARSON (2000): Shaded relief magnetic anomaly map of Italy and surrounding marine areas, Ann. Geofis., 43 (5), 983-989.

Console, R., R. Di Giovanbattista, P. Favali, G. MattiETTI and G. SMrigLIo (1989): Sismicità recente e tettonica dell'area Val Comino-Matese, in Atti del VIII Convegno GNGTS (ESA, Roma), 3-7.

Ernst, T., R. Teisseyre, A. Meloni, P. Palangio and M. MARChETTI (1997): Magnetic variation analysis for the June 1993 seismic events in Central Italy, Ann. Geofis., XL (2), 539-545.

Gasparini, P., A. Meloni and D. Patella (Editors) (1997): Magnetic, electric and electromagnetic methods in seismology and volcanology, Ann. Geofis., XL (2), pp. 368. 
Gokhberg, M.B., I.L. Gufeld, A.A. Rozhnoy, V.F. Marenko, V.S. YAmpolsky and E.A. Ponomarey (1989): Study of seismic inuence on the ionosphere by super long-wave probing of the Earth-ionosphere wave-guide, Phys. Earth Planet. Int., 57, 64-67.

HAYAKAWA, M. and Y. FuJINAWA (Editors) (1994): Electromagnetic Phenomena Related to Earthquake Prediction (Terra Scientific Publishing Co., Tokyo), pp. 677.

INGV (Istituto Nazionale di Geofisica e Vulcanologia) (2003): Seismic Bulletin (Roma).

Johnston, M. (1997): Review of electric and magnetic fields accompanying seismic and volcanic activity, Surv. Geophys., 18, 441-475.

Johnston, M. (2002). Electromagnetic fields generated by earthquakes, in International Handbook of Earthquake and Engineering Seismology, edited by W. LEE, H. KANAMORI, P. JenNingS and C. KisSLINGER (Academic Press), part A, 621-634.

Johnston, M. and M. PARRot (1997): Electromagnetic effects of earthquakes and volcanoes, Phys. Earth Planet. Int., 105, 109-118.

Mele, G., A. Meloni and P. Palangio (1994): A tectonomagnetic effect detected in Central Italy, Ann. Geofis., XXXVII (1), 17-25.

Meloni, A., P. Palangio, M. Marchetti, R. Teisseyre, T. ERNST and J. MARIANUK (1996): Central Italy magnetotelluric investigation. Structures and relation to seismic events: analysis of initial data, Ann. Geofis., XXXIX (1), 159-177.

Meloni, A., G. Mele and P. Palangio (1998): Tectonomagnetic field Observations in Central Italy 19891995, Phys. Earth Planet. Int., 105, 145-152.

Meloni, A, D. Patella, F. Vallianatos and B. Zolesi (Editors) (2001): Magnetic, electric and electromagnetic methods in seismology and volcanology, Chania Greece, Ann. Geofis., 44 (2), pp. 320.

Molchanov, O.A. and M. HaYAKAWA (1998): Subionospheric VLF perturbations possibly related to earthquakes, J. Geophys. Res., 103 (A8), 17,489-17,504.

Molchanov, O.A., O. Mazhaeva, A.N. Goliavin and M. HAYAKAWA (1993): Observation by the InterCosmos-24 satellite of ELF VLF electromagnetic emissions associated with Earthquakes, Ann. Geophysicae, 11, 431-440.
Molina, F., E. Armando, R. Balia, O Battelli, E. Bozzo, G. Budetta, G. Caneva, M. Ciminale, N. De Florentis, A. De Santis, G. Dominici, M. Donnaloia, A. Elena, V. Iliceto, R. Lanza, M. Loddo, A. Meloni, E. Pinna, G. Santarato and R. ZamBRANO (1994): Geomagnetic survey of Italy at 1979.0, Repeat Station Network and Magnetic Maps (ING, Roma), pp. 32.

Morgounov, V.A., T. ONDOH and S. NagAi (1994): Anomalous variation of VLF signals associated with strong earthquakes $(M>7.0)$, in Electromagnetic Phenomena Related to Earthquake Prediction, edited by M. HAYAKAWA and Y. FuJINAWA (Terra Scientific Publishing Company, Tokyo) 409-428.

Mueller, R.J. and M.J.S. Johnston (1998): Review of magnetic field monitoring near active faults and volcanic calderas in California: 1974-1995, Phys. Earth Planet. Inter., 105, 131-144.

Nagao, T., Y. EnOmoto, Y. Fujinawa, M. Hata, M. HayaKawa, Q. Huang, J. IzUTSU, Y. Kushida, K. MaEDA, K. Oike, S. UyedA and T. Yoshino (2002): Electromagnetic anomalies associated with 1995 Kobe earthquake, J. Geodyn., 33, 401-411.

PARRot, M. (1994): Statistical study of ELF/VLF emission recorded by a low altitude satellite during seismic events, J. Geophys. Res., 99 (23), 339-349.

PARrot, M. (1995): Electromagnetic noise due to earthquakes, in Handbook of Atmospheric Electrodynamics, edited by H. Volland (CRC Press, Boca Raton, FL), vol. 2, 2nd edition, 95-116.

PARrot, M. and M. Johnston (1993): Seismo-electromagnetic effects, Phys. Earth Planet. Inter., 77, 65-83.

PARSONS, L.W. and Z.M. WIATR (1982): Rubidium vapour magnetometer, J. Sci. Instrum., 39, 292-299.

Saraev, A.K., M.I. Pertel, P.A. Parfent'ev, V.E. ProKOF'EV and M.M. KHARLAMOV (1999): Experimental study of the Electromagnetic field from a VLF Radio set for the purposes of monitoring seismic activity in the North Caucasus, Phys. Solid Earth, 35 (2), 101-108.

WARD, S. and G. VALENSISE (1989): Fault parameters and slip distribution of the 1915 Avezzano, Italy, earthquake derived from geodetic observations, Bull. Seismol. Soc. Am., 79, 690-710. 